\title{
Infiltration of Local Immune Cells in the Sow Reproductive Tracts after Intra- Uterine and Deep Intra-Uterine Insemination with a Reduced Number of Spermatozoa is Less than Conventional Artificial Insemination
}

\author{
Padet TUMMARUK ${ }^{1)^{*}}$ and Paisan TIENTHAI ${ }^{2)}$ \\ ${ }^{1)}$ Department of Obstetrics, Gynaecology and Reproduction, Faculty of Veterinary Science, Chulalongkorn University, Bangkok and \\ ${ }^{2)}$ Department of Anatomy, Faculty of Veterinary Science, Chulalongkorn University, Bangkok 10330, Thailand
}

(Received 7 July 2010/Accepted 16 December 2010/Published online in J-STAGE 28 December 2010)

\begin{abstract}
The present study investigated the infiltration of leukocyte subpopulations in the utero-tubal junction (UTJ) and each part of the oviducts at about $24 \mathrm{hr}$ after intra-uterine insemination (IUI) and deep intra-uterine insemination (DIUI) compared to conventional artificial insemination (CAI) in sows. Fifteen crossbred Landrace $\mathrm{x}$ Yorkshire multiparous sows were used (CAI, n=5; IUI, n=5; DIUI, $\mathrm{n}=5)$. The sperm dose contained $3,000 \times 10^{6}(100 \mathrm{~m} l), 1,000 \times 10^{6}(50 \mathrm{ml})$ and $150 \times 10^{6}(5 \mathrm{~m} l)$ motile spermatozoa for CAI, IUI and DIUI, respectively. The sows were inseminated with extended fresh semen at 6 to $8 \mathrm{hr}$ prior to the expected time of ovulation. At 25.2 $\pm 1.6 \mathrm{hr}$ after insemination, the oviducts and the UTJ were collected. The tissue samples of UTJ, caudal isthmus, cranial isthmus and ampulla were transversely cut to a thickness of $5 \mu \mathrm{m}$ and stained with H\&E. The total numbers of lymphocytes, neutrophils, macrophages, eosinophils and plasma cells were determined under light microscope. It was found that the numbers of lymphocytes, eosinophils and macrophages after CAI, IUI and DIUI were not significantly different $(P>0.1)$ in both epithelial and sub-epithelial connective tissue layer of the UTJ, caudal isthmus, cranial isthmus and ampulla. Intra-epithelial neutrophils in the UTJ were higher than cranial isthmus $(P<0.05)$ and ampulla $(P<0.05)$. In the UTJ, the intra-epithelial neutrophil in the CAI group was higher than DIUI group $(P<0.01)$. Plasma cells in sub-epithelial layer of the endosalpinx in the CAI group were higher than DIUI group $(P<0.05)$ and tended to be higher than the IUI group $(P=0.08)$. In conclusion, compared to CAI, IUI and DIUI do not influence the infiltration of lymphocytes, macrophages and eosinophils in the UTJ and the oviduct prior to fertilization. But a lower number of neutrophils in the intra-epithelial layer of the UTJ and plasma cells in the sub-epithelial layers of the oviduct was observed in the DIUI group compared to CAI.
\end{abstract}

KEY WORDS: immune cell, intra-uterine insemination, oviduct, swine.

The journey of the sperm from the insemination site to the fertilization place at the middle part of the oviduct involves many factors including the female genital tract or the spermatozoa $[15,20]$. In the pig, the utero-tubal junction (UTJ) and the caudal isthmus act as a sperm reservoir to restrict sperm access to the fertilization site [4]. Recently, new devices for artificial insemination (AI) in the pig have been developed, i.e., intrauterine insemination (IUI) and deep intra-uterine insemination (DIUI) $[10,16,20,22]$. Using these techniques, the number of spermatozoa per dose can be reduced but the catheter must be passed through the cervical canal and some part of the uterine horn, and deposit semen in the uterine body (for IUI) or in one side of the uterine horn (for DIUI). It has been shown that DIUI with a reduced number of sperm resulted in a significantly lower number of sperm in the sperm reservoir at $24 \mathrm{hr}$ after insemination [22], while the sperm in the UTJ and oviducts do not differ significantly between IUI and conventional AI (CAI) [20].

After insemination, excessive sperm are eliminated by the local immune cells of the sow endometrium $[2,8]$. These immune cells are produced from either lymphoid

\footnotetext{
* Correspondance to: Tummaruk, P., Department of Obstetrics, Gynaecology and Reproduction, Faculty of Veterinary Science, Chulalongkorn University, Bangkok 10330, Thailand. e-mail: Padet.T@chula.ac.th
}

(e.g., lymphocyte, plasma cell) or myeloid lineage (e.g., neutrophil, macrophage and eosinophil) in the bone marrow [2]. Lymphocyte function is mainly for specific immune response, while neutrophil function is for the non-specific immune response and phagocytosis [2]. The infiltration of the leukocyte subpopulation in the sow uterus and oviduct in non-mated gilts [11], normal cycle sows [12] and at different time periods after CAI has been reported $[2,6,8]$. However, infiltration of the leukocyte subpopulation after IUI and DIUI has never been investigated. It is not known yet whether these two transcervical insemination techniques will cause positive or negative effect on the immune function of the sow's reproductive tracts. Earlier studies have demonstrated that lymphocytes are the dominant immune cells in the gilts' [18] and sows' endometrium [7] and most of these lymphocytes were T cells [6]. Furthermore, neutrophils and macrophages are observed in all tissue layers of the gilts/sows' endometrium, especially during the follicular phase [7, 18] and endometritis [19]. After AI, the numbers of neutrophils in the sows' endometrium is also increased [8]. Neutrophils are the earliest phagocytic cells responding to inflammation including engulfing and destroying foreign antigens and thereafter dying. Generally, neutrophils and macrophages act as the non-specific phagocytic cells in the female reproductive tract. The impaired function of neutrophils increases the susceptibility of the endometrium to uter- 
ine infection [23]. The number of neutrophils in the endometrium and the resistance to uterine infection in the pig is highest during estrus and lowest during the luteal phase $[5,12]$. After insemination, the immune cells eliminate excessive sperm in order to prepare the endometrium for embryonic development and implantation [8]. It is well established that viable sperm remains in the female reproductive tract for $24 \mathrm{hr}$ after insemination [4, 11]. Furthermore, the number of spermatozoa depositing in the sperm reservoir changes dramatically after ovulation takes place [11]. In the female reproductive tract, the infiltration of local immune cells begins as early as $3 \mathrm{hr}$ after AI [14] and remains for over $24 \mathrm{hr}$ or until an implantation takes place [8]. Furthermore, several studies have demonstrated that at the various sperm dosages used at present, the results of fertilization are quite good when the ovulation occurs within $24 \mathrm{hr}$ after insemination [16]. In our previous study [17], the number of spermatozoa in the female reproductive tract at $24 \mathrm{hr}$ after CAI, IUI and DIUI has been demonstrated but the infiltration of the local immune cells during this period has not been evaluated.

It is of interest to investigate whether or not the modification of insemination technique in the pig by reducing the number of spermatozoa and inserting the catheter through the cervix alters the infiltration of some specific immune cells. The objective of the present study was to investigate the infiltration of leukocyte subpopulations in the UTJ and each part of the oviducts at about $24 \mathrm{hr}$ after IUI and DIUI compared to CAI in sows.

\section{MATERIALS AND METHODS}

Animals and the detection of oestrus and ovulation: Fifteen crossbred Landrace $\mathrm{x}$ Yorkshire (LY) multiparous sows were used in the experiment. On the day of weaning, they were allocated to individual pens adjacent to adult boars. The sows were observed for pro-oestrus twice a day $(\mathrm{am} / \mathrm{pm})$. The sows were randomly assigned to 3 groups, i.e., CAI $(n=5)$, IUI $(n=5)$ and DIUI $(n=5)$. Transrectal ultrasonography (Echo camera SSD-550, Aloka Co. Ltd., Japan) was performed every $4 \mathrm{hr}$ using a $5 \mathrm{MHz}$ probe to examine the ovulation time in all sows [7, 20].

Collection and dilution of semen and insemination: The semen was collected from an adult proven Duroc boar. Semen with a motility of $\geq 70 \%$ was diluted, using Beltsville thawing solution (BTS) diluent. The sperm dose contained $3,000 \times 10^{6}$ motile spermatozoa in $100 \mathrm{~m} l$ for CAI, $1,000 \times$ $10^{6}$ motile spermatozoa in $50 \mathrm{~m} l$ for IUI (Deep golden pig ${ }^{\circledR}$, Minitube, Germany) and $150 \times 10^{6}$ motile spermatozoa in 5 $\mathrm{m} l$ for DIUI [10]. The sows were inseminated with a single dose of the diluted semen during the second oestrus after weaning at 6 to $8 \mathrm{hr}$ prior to the expected time of ovulation. The sows were inseminated by the CAI, IUI and DIUI techniques $[17,20]$.

Sampling procedures: The sows were general anesthetized at $25.2 \pm 1.6 \mathrm{hr}$ after insemination. The ovario-hysterectomy was performed by laparotomy. The reproductive organs were removed and immediately transferred to the laboratory. The oviducts and the proximal part of uterine horns $(1 \mathrm{~cm})$ on each side of the reproductive tracts were collected. The section was divided into 4 parts, i.e., UTJ, caudal isthmus, cranial isthmus and ampulla [20]. The spermatozoa in the lumen in each part were flushed several times with Phosphate buffer solution (PBS). After flushing, the UTJ and all parts of the oviducts were immersed in $10 \%$ neutral buffer formalin solution for further processing.

Tissue sections and histological examination: The UTJ and each part of the oviducts were cut into 4 equal sections and embedded in paraffin block. The tissue sections were transversely cut to a thickness of $5 \mu \mathrm{m}$. Every fifth serial slide section was mounted and stained with haematoxylin and eosin (H\&E). The total numbers of lymphocytes, neutrophils, macrophages, eosinophils and plasma cells in each parts of the tissue were determined under light microscope using 400x magnification. The immune cells were counted within $15,625 \mu \mathrm{m}^{2}$ of ocular micrometer for 10 areas per tissue section. A total of 32 sections per organ (left and right sides) in each sow was determined.

Statistical analysis: Data were analyzed using SAS software version 9.0 (SAS Inst. Inc., Cary, NC, U.S.A..). Numbers of lymphocytes, neutrophils, macrophages, eosinophils and plasma cells counted in epithelial and sub-epithelial layers and in each part of the oviducts were presented as means \pm standard error of the means (SEM). Due to skewing of the data, a natural $\log$ transformation was applied to the data before inclusion in the statistical models. The numbers of lymphocytes, neutrophils, macrophages, eosinophils and plasma cells (log transformation) in epithelial and sub-epithelial layers of the endosalpinx in each part of the oviduct were compared among groups using the General linear mixed model (MIXED) procedure. The model included groups (CAI, IUI, DIUI), sides (left and right) and parts of the oviduct (UTJ, caudal isthmus, cranial isthmus and ampulla) and interaction between groups and parts as fixed effects, and included animal as random effects. Leastsquared means were compared using least significant different test. Differences with $P<0.05$ were regarded to have statistical significance.

\section{RESULTS}

Infiltration of immune cells in the epithelial layer of the endosalpinx: Infiltration of intra-epithelial lymphocytes, neutrophils, macrophages in the UTJ and oviducts of sow is demonstrated in Table 1, Figs. 1a, b, 2 and 3. Plasma cells and eosinophils were not found in the epithelial layer of the endosalpinx (Fig. 1c,d). The numbers of lymphocytes, neutrophils and macrophages after CAI, IUI and DIUI in all parts of the tissue sections were not significantly different $(P>0.1)$ (Table 1). A small amount of neutrophils and macrophages was found in the UTJ and caudal isthmus in all sows and in the cranial isthmus and ampulla in some sows (Fig. 2). Across the part of the oviduct, the numbers of intra-epithelial lymphocytes, neutrophils and macrophages 
Table 1. Numbers of intra-epithelial and sub-epithelial leukocyte subpopulation in the endosalpinx of sow after conventional artificial insemination (CAI), intra-uterine insemination (IUI) and deep intra-uterine insemination (DIUI) (mean \pm SEM)

\begin{tabular}{|c|c|c|c|}
\hline Cells & CAI & IUI & DIUI \\
\hline \multicolumn{4}{|l|}{ Epithelial layer } \\
\hline Lymphocyte & $1.021 \pm 0.162^{\mathrm{a})}$ & $0.925 \pm 0.132^{\mathrm{a})}$ & $0.973 \pm 0.108^{\mathrm{a})}$ \\
\hline Neutrophil & $0.069 \pm 0.054^{a)}$ & $0.040 \pm 0.026^{\mathrm{a})}$ & $0.006 \pm 0.004^{\mathrm{a})}$ \\
\hline Macrophage & $0.015 \pm 0.006^{\mathrm{a})}$ & $0.013 \pm 0.004^{\mathrm{a})}$ & $0.020 \pm 0.008^{a)}$ \\
\hline \multicolumn{4}{|c|}{ Sub-epithelial layer } \\
\hline Lymphocyte & $1.535 \pm 0.317^{\mathrm{a})}$ & $1.595 \pm 0.195^{\mathrm{a})}$ & $1.479 \pm 0.152^{\mathrm{a})}$ \\
\hline Neutrophil & $0.111 \pm 0.049^{\mathrm{a})}$ & $0.247 \pm 0.122^{\mathrm{a})}$ & $0.095 \pm 0.027^{\mathrm{a})}$ \\
\hline Macrophage & $0.026 \pm 0.024^{\mathrm{a})}$ & $0.004 \pm 0.003^{\text {a) }}$ & $0.006 \pm 0.004^{\mathrm{a})}$ \\
\hline Eosinophil & $0.003 \pm 0.002^{\mathrm{a})}$ & $0^{\text {a) }}$ & $0.003 \pm 0.003^{\mathrm{a})}$ \\
\hline Plasma cell & $0.336 \pm 0.071^{\text {a) }}$ & $0.155 \pm 0.040^{\mathrm{a}, \mathrm{b})}$ & $0.120 \pm 0.033^{b)}$ \\
\hline
\end{tabular}

a,b) Different letters within rows differ significantly $(P<0.05)$.
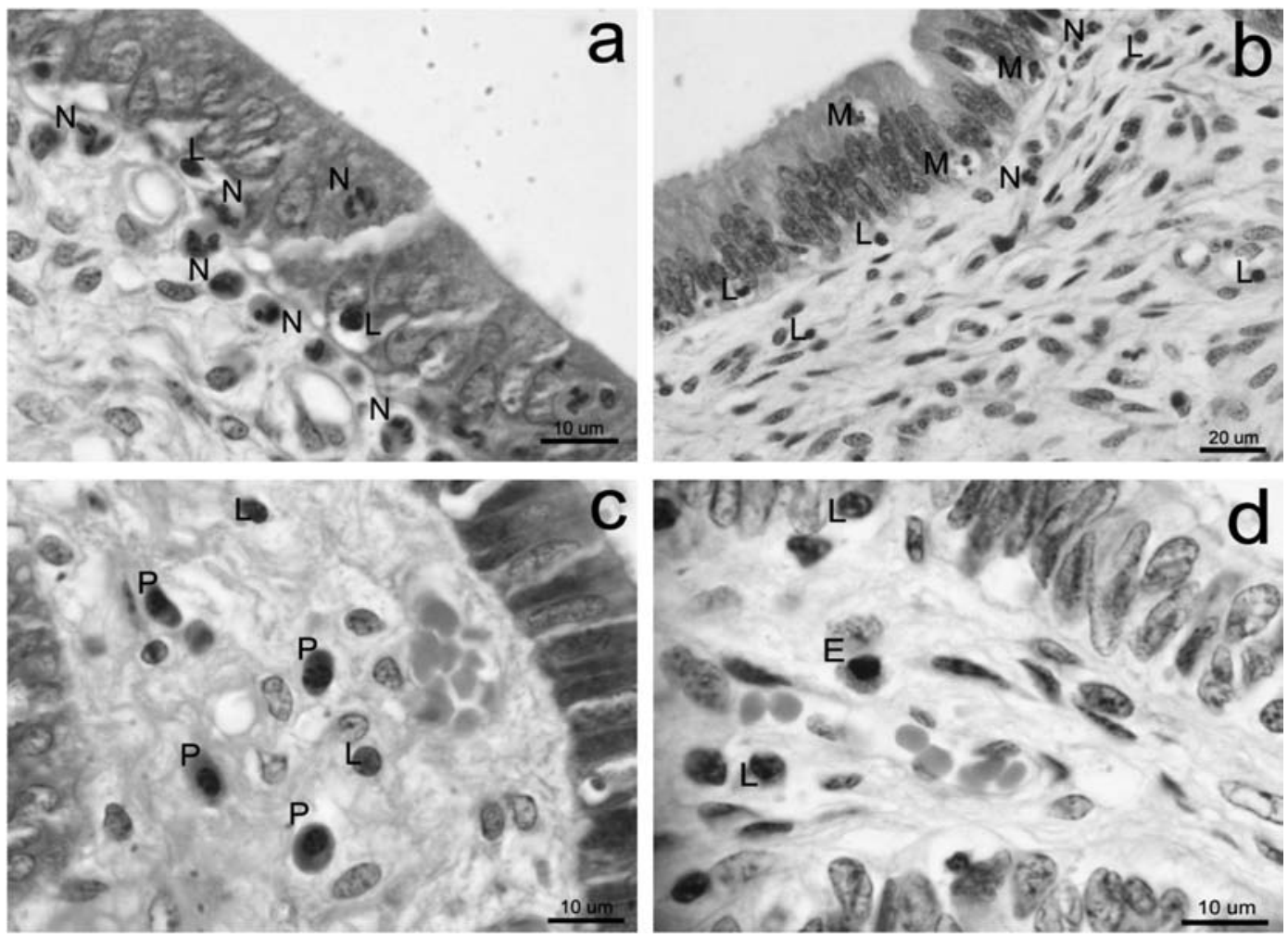

Fig. 1. Characteristics of various immune cells within the epithelial and subepithelial connective tissue layers of the utero-tubal junction (UTJ) in sows. L, lymphocyte; N, neutrophil; M, macrophage; P, plasma cell; E, eosinophil, H\&E staining.

are presented in Table 1. The leukocyte subpopulations in the epithelial layer of the endosalpinx were not significantly different among groups $(P>0.05)$. However, across the part of the oviduct, the number of intra-epithelial neutrophils in the CAI group was, on average, 10 times higher than in the DIUI groups $(P=0.28)$ (Table 1$)$. In the UTJ, the number of intra-epithelial neutrophils in the CAI group was higher than in the DIUI group $(P<0.01)$ (Fig. 3). The sizes of the leukocyte subpopulation in the intra-epithelial layers of the endosalpinx classified by part of the organs and insemination procedure are demonstrated in Fig. 3. Lymphocytes were the most common immune cells in all parts of the oviducts (Fig. 3). The numbers of intra-epithelial lymphocytes and neutrophils differed significantly among different parts of the oviduct, whereas the numbers of intra-epithelial lymphocytes were highest in the UTJ and lowest in the cranial isthmus (Fig. 2). Intra-epithelial neutrophils in the UTJ were higher than in the cranial isthmus $(P<0.05)$ and 


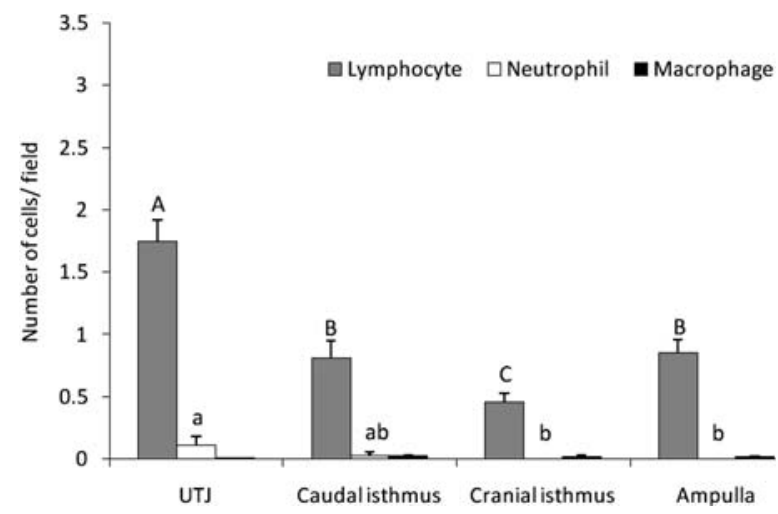

Fig. 2. Infiltration of intra-epithelial lymphocytes, neutrophils and macrophages in the UTJ, caudal isthmus, cranial isthmus and ampulla of sow at $24 \mathrm{hr}$ after artificial insemination (means \pm SEM); ${ }^{\mathrm{A}, \mathrm{B}, \mathrm{C} \text { or a,b }}$ different superscripts among parts of the oviduct differed significantly $(P<0.05)$.

ampulla $(P<0.05)$.

Infiltration of immune cells in the sub-epithelial layer of the endosalpinx: Infiltration of sub-epithelial lymphocytes, neutrophils, macrophages, eosinophils and plasma cells in the UTJ and oviducts of the sow is demonstrated in Table 1, Figs. 1a, b, 4 and 5. Sub-epithelial lymphocytes, neutrophils, macrophages and eosinophils were not significantly different among the groups (Table 1). However, the number of plasma cells in the sub-epithelial layer of the endosalpinx in the CAI group was higher than in the DIUI group $(P<0.05)$ and tended to be higher than in the IUI group $(P=0.08)$ (Table 1). This difference was most pronounced in the caudal isthmus of the AI group which was higher than for the DIUI $(P<0.05)$ and IUI groups $(P=0.07)$ (Fig. 5). On average, sub-epithelial lymphocytes and neutrophils in the UTJ were higher than in other parts of the oviducts (Fig. 4). On the other hand, the numbers of plasma cells in the ampulla $(0.360 \pm 0.065$ cells/field $)$ were higher than those in the UTJ $(0.138 \pm 0.049$ cells/field, $P<0.001)$, caudal isthmus $(0.143 \pm 0.074$ cells/field, $P<0.001)$ and cranial isthmus $(0.181 \pm 0.045, P<0.01)$ (Fig. 4). The sizes of the leukocyte subpopulations in the sub-epithelial layers of the endosalpinx classified by part of the organs and insemination procedure are demonstrated in Fig. 5. In the UTJ, sub-epithelial neutrophils in the DIUI group tended to be lower than in CAI $(P=0.15)$ and IUI groups $(P=0.07)$ (Fig. 5).

\section{DISCUSSION}

The DIUI and IUI techniques are new AI procedures in the pig. They are more invasive than the CAI technique because the catheter must pass through the cervical canal (IUI) or pass along the uterine horn (DIUI). To our knowledge, it is not known whether or not this invasive insemination causes a different inflammatory response compared to CAI. In general, the inflammatory response occurs in the endometrium a few hr after the sperm have entered the uter-
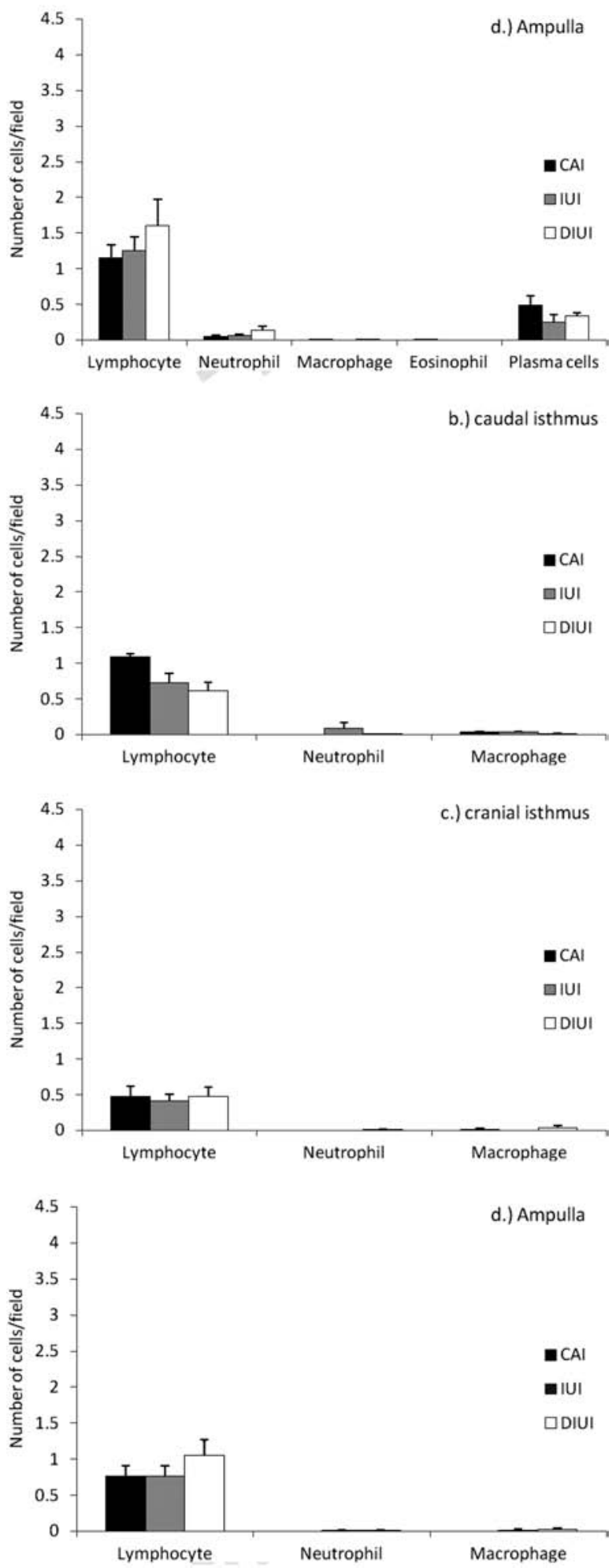

Fig. 3. Infiltration of immune cells in the intra-epithelial layers of the endosalpinx at different parts of the oviduct after conventional artificial insemination (CAI), intra-uterine insemination (IUI) and deep intra-uterine insemination (DIUI); ${ }^{\mathrm{a}, \mathrm{b}}$ different superscripts differed significantly $(P<0.05)$. 


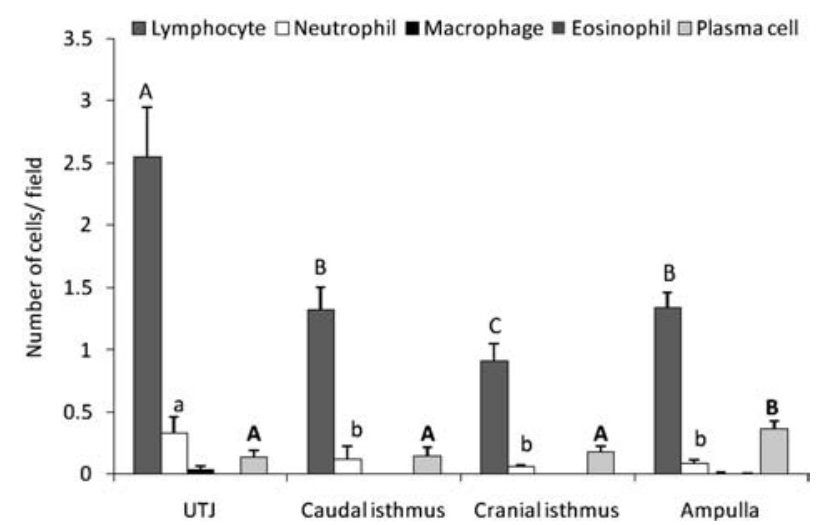

Fig. 4. Infiltration of sub-epithelial lymphocytes, neutrophils, macrophages, eosinophils and plasma cells in the UTJ, caudal isthmus, cranial isthmus and ampulla of sow at $24 \mathrm{hr}$ after artifi-

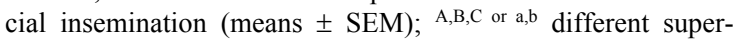
scripts among parts of the oviduct differed significantly $(P<0.05)$.

ine lumen [14]. This inflammatory response includes an increase in the number of polymorphonuclear cells (PMN) including neutrophils in order to eliminate excessive sperm in the uterine lumen. More specifically, some proteins in the boar seminal plasma play an important role in the induction of PMN cells in the sow endometrium [14]. In the present study, the numbers of inflammatory cells (neutrophils and plasma cells) in some part, especially in the UTJ, of the oviduct were higher in the CAI than the DIUI groups and also tended to be higher than in the IUI groups. The reason might be due to the number of spermatozoa depositing in the UTJ and oviduct of sows after DIUI with a reduced number of spermatozoa was significantly lower than that after CAI [17]. Since either the volume of semen or the total number of spermatozoa used for DIUI were 20 times less than CAI, some seminal plasma proteins that can induce PMN cells might be low. In the mare uterus, the compounds in the insemination dose stimulated a uterine inflammatory response (higher in number of PMN cells), which was more swift and intense as sperm concentration increased [3]. The present study indicated that less inflammatory response was found in the sow oviduct after DIUI and IUI compared to CAI. These inflammatory reactions occur due to the sperm rather than due to the passing of the catheter through the cervix and/or the uterine horn.

Lymphocytes were the most common immune cells found at about $24 \mathrm{hr}$ after insemination in all groups of the sows, while a low number of neutrophils, macrophages, eosinophils and plasma cells was also found in the sperm reservoir. The pattern of leukocyte infiltration in the sow's endosalpinx was similar to the early dioestrus stage $(\sim 70 \mathrm{hr}$ after ovulation) in the sow uterus [8] and the sow oviduct [6]. The low amount of neutrophils and macrophages indicates that the function of the non-specific immune system or phagocytosis is limited in the sperm reservoir as suggested in the previous study by Rodriguez-Martinez et al. [13].
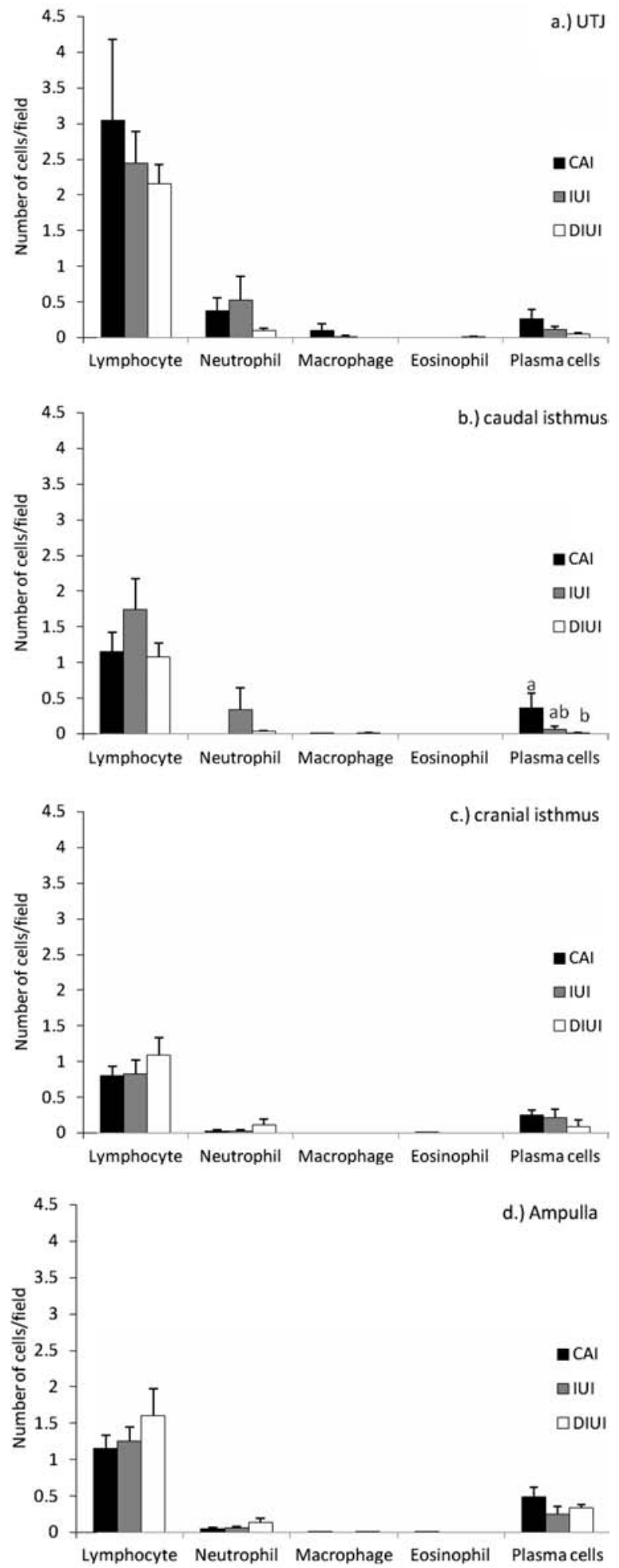

Fig. 5. Infiltration of immune cells in the sub-epithelial layer of the endosalpinx at different parts of the oviduct after conventional artificial insemination (CAI), intra-uterine insemination (IUI) and deep intra-uterine insemination (DIUI); ${ }^{\mathrm{a}, \mathrm{b}}$ different superscripts differed significantly $(P<0.05)$. 
In general, the number of sperm used for IUI and DIUI was 3 and 20 times less than for CAI $[17,20]$. Our previous study has also demonstrated that the number of sperm in the crypt of the sperm reservoir (UTJ and caudal isthmus) in the DIUI groups was also lower than that with CAI [21]. The present study indicates that the reduction in the number of sperm for IUI and DIUI did not alter the infiltration of lymphocytes, macrophages and eosinophils in the UTJ and all parts of the oviduct. However, some changes in the number of neutrophils and plasma cells were observed in some part of the oviduct. In most cases, neutrophils in the oviduct of the DIUI group were lower than in the CAI group. One reason for this might be that the number of sperm in the oviducts of sows after DIUI was lower than in CAI [21]. Neutrophils are non-specific immune cells which migrate from the endosalpinx to eliminate excessive sperm. Thus, a higher number of sperm observed in the CAI groups may cause a higher number of neutrophil infiltrations. Similarly, the number of neutrophils in the UTJ was much higher than in the upper part of the oviducts. This is due to the same reason, in that the UTJ contains more sperm than the upper part of the oviduct. The UTJ is an important barrier for the excessive sperm that attempt to reach the oviduct. It has earlier been demonstrated that the number of sperm in the female reproductive tract after CAI, IUI and DIUI was much higher in the UTJ than in the upper part of the oviduct [17, 20, 21].

In the present study, CAI with $3,000 \times 10^{6}$ motile sperm resulted in a higher number of plasma cells in the endosalpinx compared to DIUI with a reduced number of sperm. This is in contrast to an earlier study in the endometrium [8]. It was found that there was no increase in the number of plasma cells in the subepithelial connective tissue layer of the endometrium after insemination in sows. The authors also hypothesized that semen may not be the antigen that can stimulate the number of plasma cells. However, in the porcine oviduct, a higher number of plasma cells were found in the infundibulum compared to other parts [6]. In general, plasma cells produce immunoglobulin, and secrete this into the lumen [9]. This action has a significant role in the early defense against the invasion of micro-organisms at the mucosal surfaces of the endometrium as in the case for intestinal mucosa [1]. Unlike neutrophils and macrophages, plasma cells are developed from lymphoid lineage and react to pathogens in a specific manner. Noticeably, all of the sows in this study are multiparous indicating that they have been exposed to sperm several times. The presence of plasma cells in the oviduct may indicate the recognition of the sperm by the sow endosalpinx. Therefore, the higher sperm number might stimulate a higher reaction of the immune cells in the oviduct.

In conclusion, the present study proves that IUI and DIUI, as new methodologies for AI in the pig, do not influence the infiltration of lymphocytes, macrophages and eosinophils in the UTJ and all parts of the oviduct prior to fertilization. But a lower number of neutrophils and plasma cells in some part of the oviduct was observed in the DIUI group compared to CAI.

ACKNOWLDGEMENT. This study was funded by the Ratchadaphiseksomphot Endowment Fund, Chulalongkorn University. We would also like to thank Chula Unisearch, Chulalongkorn University for coordinating for language editing.

\section{REFERENCES}

1. Brandtzaeg, P., Bjerke, K., Kett, K., Kvale, D., Rognum, T.O., Scott, H., Sollid, L.M. and Valnes, K. 1987. Production and secretion of immunoglobulins in the gastrointestinal tract. Ann. Allergy 59: 21-39.

2. Dalin, A.M., Kaeoket, K. and Persson, E. 2004. Immune cell infiltration of normal and impaired sow endometrium. Anim. Reprod. Sci. 82-83: 401-413.

3. Fiala, S., Pimentel, C., Mattos, A., Gregory, R. and Mattos, R. 2007. Effect of sperm numbers and concentration on sperm transport and uterine inflammatory response in the mare. Theriogenology 67: 556-562.

4. Hunter, R.H.F., 1981. Sperm transport and reservoirs in the pig oviduct in relation to the time of ovulation. J. Reprod. Fertil. 63: 109-117.

5. Jana, B., Kucharski, J. and Ziecik, A.J. 2004. Effect of intrauterine infusion of Escherichia coli on hormonal patterns in gilts during the estrous cycle. Reprod. Nutr. Dev. 44: 37-48.

6. Jiwakanon, J., Persson, E. and Dalin, A.M. 2006. The endometrium of the anoestrous female pig: studies on infiltration by cells of the immune system. Reprod. Domest. Anim. 41: 191-195.

7. Kaeoket, K., Persson, E. and Dalin, A.-M. 2001. The sow endometrium at different stages of the oestrus cycle: studies on morphological changes and infiltration by cells of the immune system. Anim. Reprod. Sci. 65: 95-114.

8. Kaeoket, K., Persson, E. and Dalin, A.-M. 2003. Influence of pre-ovulatory insemination and early pregnancy on the infiltration by cells of the immune system in the sow endometrium. Anim. Reprod. Sci. 75: 55-71.

9. Kutteh, W.H. and Mestecky, J. 1994. Secretory immunity in the female reproductive tract. Am. J. Reprod. Immunol. 31: 4046 .

10. Martinez, E.A., Vazquez, J.M., Roca, J., Lucas, X., Gil, M.A., Parrilla, I., Vazquez, J.L. and Day, B.N. 2001. Successful nonsurgical deep intrauterine insemination with small number of spermatozoa in sows. Reproduction 122: 289-296.

11. Mburu, J.N., Einarsson, S., Lundeheim, N. and RodriguezMartinez, H. 1996. Distribution, number and membrane integrity of spermatozoa in pig oviduct in relation to spontaneous ovulation. Anim. Reprod. Sci. 45: 109-121.

12. Preyapat, P., Charunmethee, P., Sinwat, P., Teamsuwan, Y. and Tummaruk, P. 2009. Histopathology and distribution of inflammatory cells in the endometrium, cervix and vagina of gilts culled due to vaginal discharge. J. Appl. Anim. Sci. 2: 3345.

13. Rodriguez-Martinez, H., Nicander, L., Viring, S., Einarsson, S. and Larsson, K. 1990. Ultrastructure of the uterotubal junction in preovulatory pigs. Anat. Histol. Embryol. 19: 16-36.

14. Rodriguez-Martinez, H., Saravia, F., Wallgren, M., Martinez, E.A., Sanz, L., Roca, J., Vazquez, J.M. and Calvete, J.J. 2010. Spermadhesin PSP-I/PSP-II heterodimer induces migration of polymorphonuclear neutrophils into uterine cavity of the sow. 
J. Reprod. Immunol. 84: 57-65.

15. Rodriguez-Martinez, H., Saravia, F., Wallgren, M., Tienthai, P., Johannisson, A., Vazquez, J.M., Martinez, E., Roca, J., Sanz, L. and Calvete, J.J. 2005. Boar spermatozoa in the oviduct. Theriogenology 63: 514-535.

16. Soede, N., Wetzels, C., Zondag, W., De Koning, M. and Kemp, B. 1995. Effects of time of insemination relative to ovulation, as determined by ultrasonography, on fertilization rate and accessory sperm count in sows. J. Reprod. Fertil. 104: 99-106.

17. Sumransap, P., Tummaruk, P. and Kunavongkrit, A. 2007. Sperm distribution in the reproductive tract of sows after intrauterine insemination. Reprod. Domest. Anim. 42: 113117.

18. Teamsuwan, Y., Kaeoket, K., Tienthai, P. and Tummaruk, P. 2010. Morphological changes and infiltration of immune cells in the endometrium of anoestrus gilt in relation to the ovarian appearance and serum progesterone. Thai J. Vet. Med. 40: 2129.

19. Tummaruk, P., Kesdangsakonwut, S., Prapasarakul, N. and
Kaeoket, K. 2010. Endometritis in gilts: reproductive data, bacterial culture, histopathology, and infiltration of immune cells in the endometrium. Comp. Clin. Pathol. 19: 575-584.

20. Tummaruk, P., Sumransap, P., Techakumphu, M. and Kunavongkrit, A. 2007. Distribution of spermatozoa and embryos in the female reproductive tract after unilateral deep intra uterine insemination in the pig. Reprod. Domest. Anim. 42: 603-609.

21. Tummaruk, P. and Tienthai, P. 2010. Number of spermatozoa in the crypts of the sperm reservoir at about $24 \mathrm{~h}$ after a lowdose intrauterine and deep intrauterine insemination in sows. Reprod. Domest. Anim. 45: 208-213.

22. Watson, P.F. and Behan, J.R. 2002. Intrauterine insemination of sows with reduced sperm numbers: results of commercially based trial. Theriogenology 57: 1683-1693.

23. Wulster-Radeliffe, M.C., Seals, R.C. and Lewis, G.S. 2003. Progesterone increase susceptibility of gilts to uterine infections after intrauterine inoculation with infection bacteria. $J$. Anim. Sci. 81: 1242-1252. 